\title{
Effects of rural bus stops on travel time and reliability
}

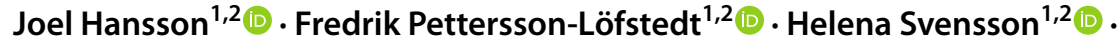 \\ Anders Wretstrand ${ }^{1,2}$ (i)
}

Accepted: 19 July 2021 / Published online: 16 August 2021

(c) The Author(s) 2021

\begin{abstract}
Due to relatively low patronage levels, rural bus stops are sometimes questioned in order to improve travel time and reliability on regional bus services. Previous research into stop spacing has focused on urban areas, which means that there is a lack of knowledge regarding the effects of bus stops in regional networks, with longer distances, higher speeds, and lower passenger volumes, in general. The present study addresses this knowledge gap by analysing the effects of bus stops on a regional bus service regarding average travel times, travel time variability, and ontime performance. This is done by statistical analysis of automatic vehicle location (AVL) data, using a combination of methods previously used for analysis of rail traffic and urban bus operations. The results reveal that bus stops that are only used sporadically have a limited impact on average travel times, in general. In contrast, they are all the more influential on travel time variability, and, in turn, on on-time performance. On the studied bus service, the number of stops made have a far greater impact on travel time variability than any of the other included variables, such as the weather or traffic conditions during peak hours. However, the results suggest that rural bus stops have a much lower impact than what we define as secondary bus stops in urban areas. Consequently, by primarily focusing on bus stop consolidation in urban areas, it is possible to significantly improve service reliability without impairing rural coverage.
\end{abstract}

Keywords Regional public transport · Rural accessibility · Stop spacing · Delays · Travel time variability $\cdot$ Bus service planning

Joel Hansson

joel.hansson@tft.lth.se

Extended author information available on the last page of the article 


\section{Introduction}

Bus stop locations and stop spacing are central elements in public transport planning. Essentially, stop spacing implies a trade-off between coverage and patronage (Walker 2008). A reduction in the number of stops will make the service inaccessible to some citizens along the route; more stops will make the service slower and travel times less predictable. Increased travel time and reduced reliability in turn lead to decreased patronage. The trade-off is far from trivial, as there are many aspects to consider as well as a complex dynamic in the interplay between these aspects. For example, the primary effects of stop spacing on travel time and reliability in turn affect operating cost and fleet size. Alternatively, lower costs can be converted to a higher quality of service, for example in the form of higher service frequencies (Stewart and El-Geneidy 2016). These so-called secondary effects occur at increasing scale as the primary effects on travel time and reliability increase (Currie 2016). Interestingly, there is also a loop back to coverage, as changes in travel time, reliability, and frequency affect access distances. A higher quality of service means that passengers are willing to accept longer access distances to reach the public transport service (Mulley et al. 2018; van Soest et al. 2020; Hansson et al. 2021).

Previous research into stop spacing has focused on urban areas, typically studying either the effects of bus stop consolidation (e.g. El-Geneidy et al. 2006; Shrestha and Zolnik 2013) or developing methods for assessing optimal stop locations (e.g. Murray and Wu 2003; Tirachini 2014; Stewart and El-Geneidy 2016). The importance of taking different land use types and densities into account is acknowledged (Chen et al. 2016), but still within the urban realm. The perspectives of rural areas and regional public transport seem to be overlooked. The primary effects in question-network coverage, travel time, and reliability-are commonly all among the top priorities for regional passengers (Hansson et al. 2019). However, based on the identified set of literature, the trade-off between these attributes, in terms of stop spacing, is not particularly well understood in regional networks, which cover both urban and rural areas.

The regional scale and rural setting mean different preconditions for the tradeoff. Longer distances, higher speeds, and lower passenger volumes are typical features distinguishing regional from urban public transport (Luke et al. 2018). All of these features have important implications for stop spacing. First, long trip distances imply longer access distances in general, and that cars and bicycles are more prominent access modes to bus stops (Martens 2004; Nielsen et al. 2005; Vijayakumar et al. 2011; Midenet et al. 2018). Second, high maximum speeds mean that each stop has a greater impact on travel times and delays, due to longer deceleration and acceleration times. Third, low passenger volumes affect the consistency of stopping patterns. Stops with passenger activity (boardings or alightings) only on a small proportion of the available bus trips will cause travel time fluctuations, which may in turn cause decreased reliability (Stewart and El-Geneidy 2016).

The purpose of this study is to increase knowledge regarding the impact of rural bus stops. An example of a rural bus stop is shown in Fig. 1. The bus stops 


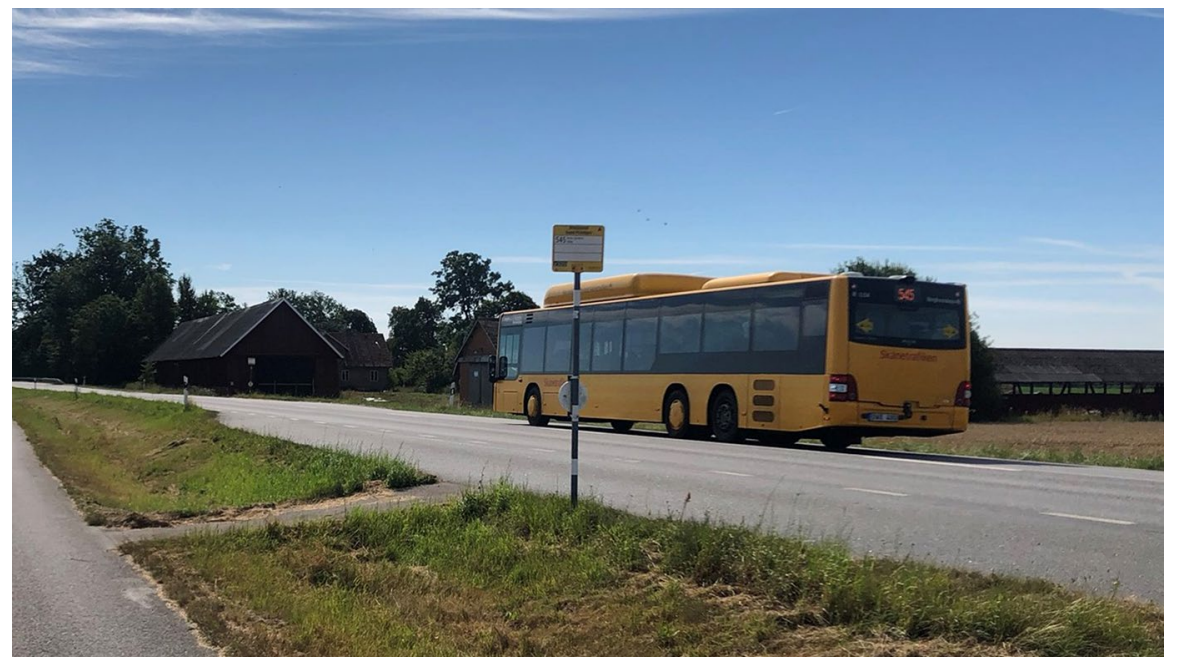

Fig. 1 An example of a rural bus stop on the studied bus service

in question are located between villages and towns on regional bus services. The existence of these bus services often depends on interurban trips, but they commonly also serve rural areas along the route as well as local collection and distribution of passengers in urban areas (White 2016). Many rural bus stops are characterised by relatively low levels of passenger activity, but may still be crucial for maintaining a certain level of coverage in rural areas. This coverage is essential for parts of the rural population who depend on public transport for their everyday mobility (Berg and Ihlström 2019), and it may also be associated with symbolic values regarding the possibility to live in rural areas outside the rural cores (Pettersson 2018). These symbolic values are possibly associated with so-called non-use values, whose importance depends on the number of available transport options (Bondemark and Johansson 2017). Consequently, the potential removal of bus stops can cause considerable resistance among residents and their local politicians, regardless of the low levels of passenger activity. A natural argument with this resistance is the assumption that rural bus stops hardly affect overall travel times, as buses rarely need to stop there.

The aim of the present study is to explore this assumption, and thus increase knowledge about the trade-off between coverage and patronage on regional bus services, by looking into the effects of rural bus stops regarding different aspects of travel time and reliability:

- What are the effects on average travel times?

- What are the effects on travel time variability and on-time performance?

The analyses are carried out at two different scales to be able to discern the effects of individual stops as well as aggregated effects on the route level. This is done by combining a method previously used for investigating rail traffic delays (Palmqvist 
et al. 2017) with another method developed for detailed statistical analysis of service reliability in bus operations (El-Geneidy et al. 2011), and summary statistics concerning stop patterns and on-time performance. The present study makes use of an adaption of these methods, specifically for exploring the impact of different types of bus stops.

\section{Methods}

To be able to discern the effects of different types of bus stops, the analysis is based on a categorisation regarding the location and function of the stops. Three categories are defined and used, of which category 3 corresponds to the rural bus stops that are the focal point of the analysis:

1. Main bus stop in an urban area (town or village). Bus stops in this category are typically located in the centre of an urban area, and they also typically have higher levels of passenger activity than other nearby bus stops do.

2. Secondary bus stops in urban areas, i.e. bus stops in towns or villages that are not in category 1.

3. Rural bus stops (outside urban areas), located en route between villages and towns.

A key notion in the categorisation is 'urban areas', which may have slightly varying meanings from an international perspective. The present study was done in a Swedish context, where an urban area is defined as a contiguous built-up area with at least 200 residents and no more than $200 \mathrm{~m}$ between houses (Statistics Sweden 2020).

Travel time is a compound of different components, such as access trip time, waiting time, and in-vehicle trip time. The analysis in this article is centred on the operational equivalent of in-vehicle trip time: bus travel time. Bus travel time is the amount of time it takes a bus to travel along its route, and it can be divided into two main components: run time and dwell time (Büchel and Corman 2020).

Reliability is assessed through measures of travel time variability and on-time performance. Travel time variability is the variability in travel time between different bus trips on the same route. In this study, travel time variability is evaluated through the reliability buffer index, which is the relative difference between the 95 th percentile of travel time and the average travel time (Hu and Shalaby 2017). In contrast, on-time performance is a timetable-based measure of reliability, measured by the fraction of services with schedule deviation within some defined threshold values (Zhao et al. 2013). In this study, on-time performance is measured by the percentage of buses arriving less than 3 min later than scheduled arrival. The measure in this study is only used for arrival times at the terminus, so early arriving buses and buses arriving up to 3 mins behind schedule are considered to be on time. The 3 -mins threshold is commonly used in the regional context of the case analysed in this article. 
To evaluate bus travel times and on-time performance, the core of the analysis is based on automatic vehicle location (AVL) data. The AVL data used in this study contain time logs at each bus stop along the route, with scheduled and actual arrival and departure times. As such, it represents a typical, commonly available AVL dataset, offering the possibility to analyse large amounts of bus trips (Büchel and Corman 2020). To supplement the AVL data, two other datasets were added. First, in order to include passenger activity (boardings and alightings) in the analysis, information was retrieved from automatic passenger counting systems (APC) onboard. Second, a dataset of weather observations was added to include the effects of weather conditions.

To be able to measure the impact of different types of bus stops, both in detail and on an aggregated level, assessments were carried out at two different scales: at the time-point segment level and at the route level. As illustrated in Fig. 2, a timepoint segment is a route segment between two consecutive time points, i.e. major bus stops where early arriving buses are held to adjust to the schedule. Time points are typically category 1 bus stops according to the categorisation used in this study. As dwell time at time points is excluded at this level of analysis, bus travel times are not blurred by schedule adjustment time. This enables the use of detailed statistical analysis to understand the causes of travel time variability (El-Geneidy et al. 2011). The route level analysis, on the other hand, relies on summary statistics to illustrate the aggregate effects of stop pattern consistency on travel time variability and ontime performance.

The time-point segment analysis is based on a method previously developed for analysing delays in rail traffic (Palmqvist et al. 2017), using a combination of $t$-tests, plots for different explanatory variables against average bus travel times, and multivariate regression models. First, Welch's $t$-test was used to gain an initial understanding, depicting statistical significance and effect size of the explanatory variables on bus travel time between time points. To this end, for each $t$-test, the dataset was segmented into two groups based on the value of the explanatory variable, e.g. temperatures above or below zero. Second, to get a more nuanced picture, each explanatory variable was binned into a larger number of bins and plotted against average bus travel time. With one exception, these plots are not presented in the article, but the main results are reproduced in text. The results of the $t$-tests and the plots serve as a basis for the selection and transformation of appropriate variables to include in the final step of the time-point segment analysis, the ordinary least square regression models. Three different regression models were estimated, for three different dependent variables:

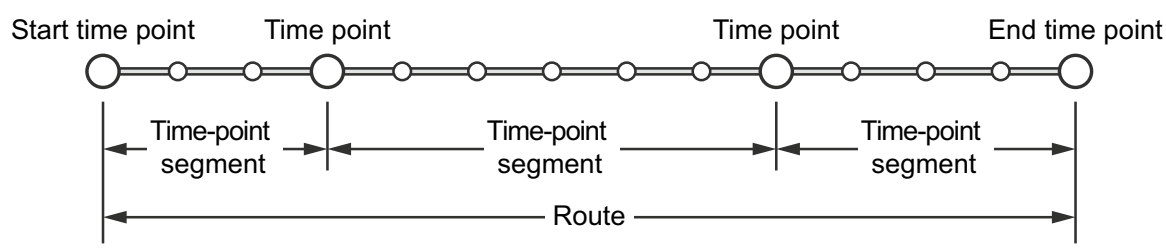

Fig. 2 Schematic diagram of the two levels of analysis: time-point segment and route 
- bus travel time, to be able to compare the influence of bus stops with other factors

- $\quad$ run time, to determine additional time for deceleration and acceleration at bus stops en route

- dwell time at bus stops along the segment, to produce separate estimates of technical dwell time and dwell time related to passenger activity.

The variables included in the analyses are described in Table 1. The focal relationship in the study is between the number of stops made and travel time. The actual number of stops made on a specific bus trip depends on the passenger activity at the intermediate bus stops, since buses do not stop at intermediate bus stops without any boardings or alightings. In other words, the focus of the study is on how the variability of the actual number of stops made affects the travel time variability. To be able to compare the impact of the bus stops with other factors, and to control the influence of these factors on the focal relationship, variables concerning day type, time of day, delay status, weather conditions, and passenger activity were included in the analyses. The selection of explanatory variables is based on previous studies on travel time variability (El-Geneidy et al. 2011; Palmqvist et al. 2017), combined with data availability considerations. Infrastructure variables were not included, due to the small number of time-point segments and, consequently, a

Table 1 Description of variables used in the time-point segment analyses. Bus travel time, run time, dwell time, and excess bus travel time are the dependent variables

\begin{tabular}{|c|c|c|}
\hline Variable & Unit & Description \\
\hline Bus travel time & s & $\begin{array}{l}\text { Time between departure from a time point and arrival at the subse- } \\
\text { quent time point }\end{array}$ \\
\hline Run time & $\mathrm{s}$ & $\begin{array}{l}\text { Time spent between bus stops, i.e. bus travel time excluding dwell } \\
\text { time }\end{array}$ \\
\hline Dwell time & $\mathrm{s}$ & Time spent at bus stops along the segment \\
\hline Excess bus travel time & - & Ratio between bus travel time and free-flow run time \\
\hline Free-flow run time & $\mathrm{s}$ & $\begin{array}{l}\text { Minimum run time, estimated through division of distance by speed } \\
\text { limit }\end{array}$ \\
\hline Day type & - & Workday (1-5), Saturday (6), or Sunday (7) \\
\hline Time of day & - & Hour of planned arrival at the end of the segment \\
\hline Schedule deviation at start & $\mathrm{s}$ & $\begin{array}{l}\text { Deviation from the schedule at the beginning of the time-point seg- } \\
\text { ment, where negative values indicate early departures and positive } \\
\text { values indicate delayed departures }\end{array}$ \\
\hline Temperature & ${ }^{\circ} \mathrm{C}$ & Air temperature, measured hourly \\
\hline Precipitation & $\mathrm{mm} / \mathrm{h}$ & Amount of rain or snowfall during $1 \mathrm{~h}$ \\
\hline Wind & $\mathrm{m} / \mathrm{s}$ & Average wind speed over a 10 -min period, measured hourly \\
\hline Snow & $\mathrm{m}$ & Snow depth, measured daily \\
\hline Stops made & - & $\begin{array}{l}\text { Number of stops made at intermediate bus stops, in total or per bus } \\
\text { stop category }\end{array}$ \\
\hline Boardings & - & Number of boarding passengers at intermediate bus stops \\
\hline Alightings & - & Number of alighting passengers at intermediate bus stops \\
\hline
\end{tabular}


too small variability of the infrastructure conditions. However, the effects of varying traffic conditions are captured by the day type and time of day variables.

To be able to analyse travel times across different time-point segments with differing lengths and speeds, the free-flow run time on each of the segments was used as a basis for the analyses on this level. The free-flow run time corresponds to the minimum run time on the segment, in no-traffic conditions and without any intermediate stops. To keep the calculations simple, the free-flow run time in this study was estimated for each time-point segment through division of distance by speed limit. In practice, there are more factors to take into account, such as turns where buses need to slow down. However, the simple estimate was deemed accurate enough for the purpose of this study.

The route level analysis was carried out to understand the aggregate effects over several time-point segments. First, the variability in stopping patterns on the route level was analysed through descriptive statistics of central locations and variability, in each bus stop category and in total. Second, the influence of this stopping pattern variability on the travel time variability was assessed by calculating the reliability buffer index depending on the number of stops made. Third, the effects on on-time performance were evaluated in a similar manner, to assess also how on-time performance varies with the number of stops made. On-time performance is measured for arrivals at the end time point on the route.

\section{Case}

The bus service analysed in this study, route 545 , is a $50 \mathrm{~km}$ long connection between the southern Swedish towns of Osby (population 7700) and Kristianstad (population 41,300). A map of the route is shown in Fig. 3. Through trips between Osby and Kristianstad are rare on the bus service, as both towns are connected through the rail network, which offers a faster alternative. Thus, the main purpose of route 545 is to provide connections to the five smaller towns and villages en route. The main bus stops (bus stop category 1) in these five urban areas constitute the time points on the service, which means that there are six time-point segments.

The bus stops along the route are located around every 400-1000 $\mathrm{m}$ in urban areas, but are more widely spaced outside of urban areas, depending on the location of population. All in all, there are 34 bus stops along the route. As shown in Fig. 4, almost half of them are located outside urban areas (category 3 ). However, the passenger activity (number of boardings and alightings) at these bus stops corresponds to just $2 \%$ of the total amount of passenger activity along the route. Thus, roughly $98 \%$ of the passenger activity takes place at the 19 bus stops located in urban areas. Of these, the seven main bus stops (category 1, including the two termini) dominate in terms of passenger activity, despite the fact that they are outnumbered by the secondary bus stops (category 2).

The bus stop categories differ not only in terms of numbers and passenger activity, but also regarding infrastructure conditions. The main bus stops (category 1) are generally terminals, separated from other traffic (with one exception: Bjärlöv, where the main bus stop is located on the shoulder of the main road). The other 


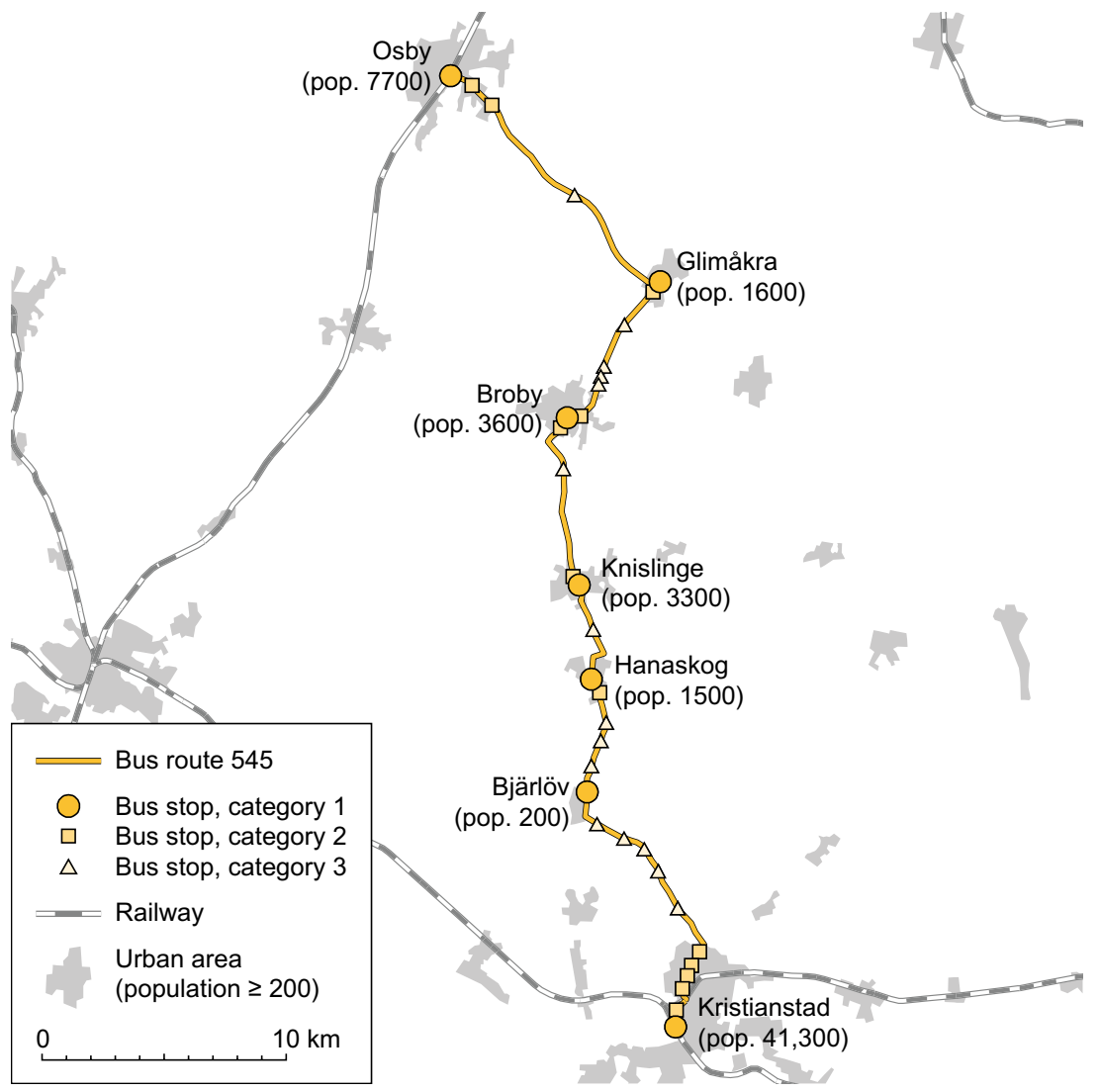

Fig. 3 Map of the analysed bus service. The bus stops in category 1 are also time points

Number of bus stops

7

15

12
Passenger activity

$2 \%$

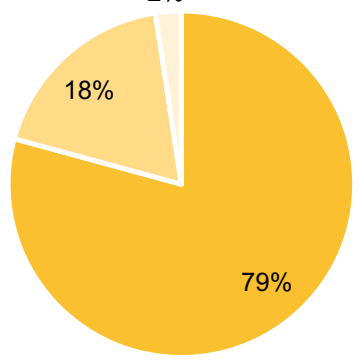

Category 1: Main bus stops in urban areas

Category 2: Secondary bus stops in urban areas

Category 3: Rural bus stops

Fig. 4 Number of bus stops and passenger activity per bus stop category 
bus stops (category 2 and 3) are typically bus bays, or in some cases in-lane bus stops, with important differences between the bus stop categories regarding speed limits. The secondary bus stops in urban areas (category 2) are located along roads with speed limits $40-60 \mathrm{~km} / \mathrm{h}$, and the rural bus stops (category 3 ) are located along roads with higher speed limits, $80-90 \mathrm{~km} / \mathrm{h}$. All roads along the route are generally uncongested.

The choice of route 545 as the case for this study was not only based on the distinctive features of the different bus stop categories, but also on the relatively generous frequency. A high frequency means that an extensive set of data is available for analysis. Buses between Osby and Kristianstad depart hourly all days of the week, and every half hour during peak hours. On the section between Broby and Kristianstad (approximately $30 \mathrm{~km}$ ), the frequency is more than doubled, overall. There, buses depart every 10 min during peak hours.

Southbound bus trips made during 2019 were chosen for the analysis, corresponding to a total of 17,471 bus trips and 84,865 observations on the time-point segment level. The AVL data were subjected to a detailed scan to remove records with errors at one or several bus stops along the segment $(N=17,775)$ as well as extremes with bus travel times more than twice as long as the scheduled travel time $(N=22)$. This means that 67,068 time-point segment observations $(79 \%)$ remained in the sample for further analysis, whereas 24,944 records (29\% of the total sample) were associated with APC equipped buses and could thus be linked to data on passenger activity.

To be able to include as many bus trips as possible in the route level analysis, this part of the study focuses on the common section for both trip patterns in the timetable: Broby-Kristianstad. Analogous to the time-point segment level, records with errors at any of the bus stops along the route were removed $(N=6825)$ together with extremes with bus travel times more than twice as long as the scheduled travel time $(N=1)$. This means that 10,645 route level observations $(61 \%)$ remained in the sample for further analysis. The larger share of missing AVL data at the route level is explained by a larger risk of data errors at intermediate bus stops, simply due to a larger number of bus stops on the route than on any of the individual time-point segments.

\section{Results}

\subsection{Time-point segment analysis}

Statistics for the analysed time-point segments are shown in Table 2. As can be seen in the table, the time-point segments differ substantially in terms of distances and average travel times. The numbers of observations also vary, depending on a more frequent service on the four southernmost segments and varying amounts of missing data. However, the travel time variability is relatively stable across the different time-point segments, expressed in the table by the reliability buffer index (RBI)the relative difference between the 95 th percentile and the average travel time. 
Table 2 Summary statistics for the analysed time-point segments

\begin{tabular}{llllll}
\hline Time-point segment & Sample size & Distance & $\begin{array}{l}\text { Free-flow run } \\
\text { time }\end{array}$ & $\begin{array}{l}\text { Average travel } \\
\text { time }\end{array}$ & RBI \\
\hline Osby-Glimåkra & 4714 & $12.9 \mathrm{~km}$ & $722 \mathrm{~s}$ & $831 \mathrm{~s}$ & $16.6 \%$ \\
Glimåkra-Broby & 6303 & $7.3 \mathrm{~km}$ & $424 \mathrm{~s}$ & $504 \mathrm{~s}$ & $17.0 \%$ \\
Broby-Knislinge & 14,494 & $7.8 \mathrm{~km}$ & $426 \mathrm{~s}$ & $566 \mathrm{~s}$ & $16.8 \%$ \\
Knislinge-Hanaskog & 15,315 & $4.4 \mathrm{~km}$ & $279 \mathrm{~s}$ & $349 \mathrm{~s}$ & $16.0 \%$ \\
Hanaskog-Bjärlöv & 14,816 & $5.0 \mathrm{~km}$ & $253 \mathrm{~s}$ & $306 \mathrm{~s}$ & $21.4 \%$ \\
Bjärlöv-Kristianstad & 11,426 & $12.4 \mathrm{~km}$ & $668 \mathrm{~s}$ & $915 \mathrm{~s}$ & $18.4 \%$ \\
\hline
\end{tabular}

To ease comparison across different time-point segments, bus travel time was transformed in the $t$-tests and plots to a variable called excess bus travel time, defined as the ratio between bus travel time and free-flow run time. As an example, a value of 1.3 means that the bus travel time is $30 \%$ longer than the free-flow run time. The average free-flow run time in the sample is $416 \mathrm{~s}$, so each percentage point corresponds to roughly $4.2 \mathrm{~s}$ on average.

The $t$-test results are reported in Table 3, comparing the mean value and standard deviation of excess bus travel time for different groups of the sample based on the values of each of the explanatory variables. As can be seen on the $p$-values in the table, the $t$-tests indicate that all the studied variables have a statistically significant impact on the excess bus travel time (on the 5\% level), but due to the large sample size, statistical significance can be found even for weak effects (Lin et al. 2013). The difference between the means is relatively small in some cases, resulting in low estimates of the effect size. The effect size, i.e. the amount of impact a variable has on the excess bus travel time, is in the table estimated through Cohen's $d$. As a rule of thumb, $d$ values of $0.8,0.5$ and 0.2 represent large, medium, and small effect sizes, respectively (Fritz et al. 2012). Thus, the results indicate that the number of stops made has a large amount of impact, with a substantially higher $d$ value than any of the other studied variables.

Table 3 Results of Welch's $t$-test, using excess bus travel time as dependent variable

\begin{tabular}{llllllllll}
\hline Variable & Value & Mean & $S D$ & Value & Mean & $S D$ & $t$ & $p$ & Cohen's \\
\hline $\begin{array}{l}\text { Day type } \\
\begin{array}{l}\text { Time of day (hour, week- } \\
\text { days only) }\end{array}\end{array}$ & $1-5$ & 1.273 & 0.148 & $6-7$ & 1.234 & 0.141 & 26.4 & $<0.001$ & 0.26 \\
$\begin{array}{l}\text { Schedule deviation at start } \\
\quad(\mathrm{s})\end{array}$ & $>0$ & 1.320 & 0.162 & $\neq 7$ & 1.268 & 0.146 & 22.8 & $<0.001$ & 0.35 \\
$\quad$ Temperature $\left({ }^{\circ} \mathrm{C}\right)$ & & & 0.147 & $\leq 0$ & 1.247 & 0.150 & 14.8 & $<0.001$ & 0.16 \\
Precipitation $(\mathrm{mm} / \mathrm{h})$ & $>0$ & 1.271 & 0.153 & $>0$ & 1.266 & 0.147 & 2.4 & 0.016 & 0.03 \\
Wind $(\mathrm{m} / \mathrm{s})$ & $>2$ & 1.271 & 0.147 & 0 & 1.266 & 0.148 & 3.7 & $<0.001$ & 0.04 \\
Snow $(\mathrm{m})$ & $>0$ & 1.283 & 0.154 & 0 & 1.265 & 0.147 & 7.8 & $<0.001$ & 0.12 \\
Stops made & $>0$ & 1.332 & 0.142 & 0 & 1.203 & 0.124 & 124.5 & $<0.001$ & 0.96 \\
\hline
\end{tabular}


However, as $t$-tests are limited to comparing two groups at a time, these results merely represent the first step of the analysis. To obtain a more nuanced picture, excess travel time was also plotted against each of the variables.

An example is presented in Fig. 5, illustrating how bus travel times vary over the course of the day. As shown in the diagram, there are distinct peaks at 7 a.m. and 4 p.m. Furthermore, travel times drop significantly after 7 p.m. Analogous plots for Saturdays and Sundays reveal that travel times are more stable during weekends, at levels similar to weekdays after 7 p.m. As a result, the day type and time of day variables were transformed into three dummy variables in the regression models: a.m. peak (weekdays 07:00-07:59), p.m. peak (weekdays 16:00-16:59), and offpeak (weekdays from 19:00, Saturdays, and Sundays). The reference category can be interpreted as inter-peak hours (weekdays before 7 p.m. except peak hours).

The impact of deviation from the schedule at the beginning of the time-point segment is also more complex than what is revealed by the $t$-tests. The shortest bus travel times are found around zero deviation, i.e. when buses depart on time. Both early and delayed departures are associated with longer travel times. To fit the linear regression models, this variable was therefore split into two separate variables: one with early departures (negative values, otherwise zero) and one with actual delays at departure (positive values, otherwise zero).

The weather variables seem to have less of an impact on the bus travel time. Based on the plots for these variables, precipitation, wind, and snow were all assumed to be linearly related to bus travel time. The exception is temperature, which was replaced by a dummy variable for temperatures at or below zero.

Boardings and alightings were not included in the $t$-tests, as that would not add any useful information, but the plots indicate decreasing time spent for each

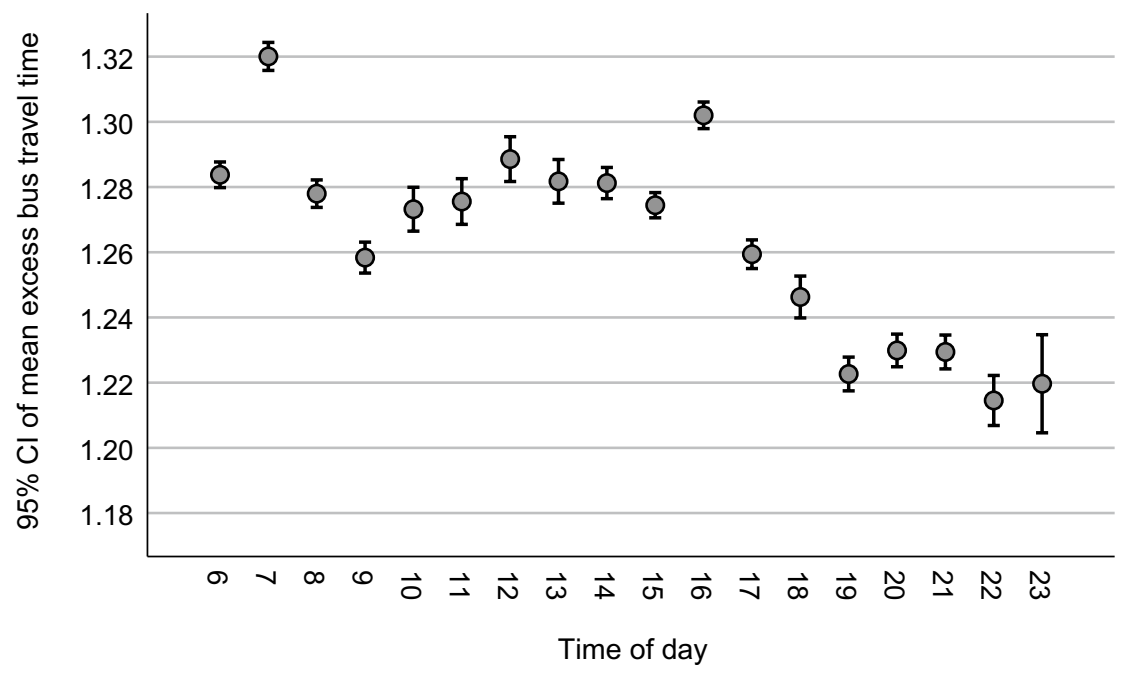

Fig. 5 Mean excess bus travel time against time of day on weekdays. Excess bus travel time is the ratio between bus travel time and free-flow run time. Error bars represent $95 \%$ confidence intervals of the mean values 
additional passenger. To deal with this non-linear feature, squared terms for boardings and alightings were added to the regression analysis.

The variables, in some cases transformed according to the results of the $t$-tests and plots, were then incorporated in three regression models with different dependent variables: bus travel time, run time, and dwell time. Analogous to the $t$-test results, many of the explanatory variables have low $p$-values in the regression models, due to the large sample size. This means that when interpreting the results, it is important to keep in mind the difference between statistical and practical significance (Lin et al. 2013). Consequently, the description of the results is focused on coefficients $(b)$, variability of the explanatory variables, and standardised coefficients $(\beta)$. The standardised coefficients refer to how many standard deviations the dependent variable will change per standard deviation increase in the explanatory variable. Furthermore, 95\% confidence intervals for the unstandardised coefficients are reported in the regression result tables, adding information about the ranges for the actual magnitudes of the parameters of interest.

The first model, the bus travel time model, is presented in Table 4. As a basis, a coefficient $(b)$ of 1.15 for free-flow run time means that the average bus travel time will be $15 \%$ longer than the calculated free-flow time if all other variables are held at zero. The other variables then explain the travel time variability on each timepoint segment. For example, bus travel times during the a.m. peak are on average $20 \mathrm{~s}$ longer than off-peak travel times if all other variables are held at their average

Table 4 Regression results with bus travel time (in seconds) as the dependent variable

\begin{tabular}{|c|c|c|c|c|c|}
\hline & $b$ & $95 \% \mathrm{CI}$ & $\beta$ & $t$ & $p$ \\
\hline Constant & 9.016 & {$[7.480,10.552]$} & - & 11.5 & $<0.001$ \\
\hline Free-flow run time (s) & 1.149 & {$[1.146,1.152]$} & 0.821 & 718.8 & $<0.001$ \\
\hline \multicolumn{6}{|l|}{ Period (ref.: inter-peak) } \\
\hline a.m. peak & 13.535 & {$[11.976,15.093]$} & 0.016 & 17.0 & $<0.001$ \\
\hline p.m. peak & 11.321 & {$[9.723,12.918]$} & 0.013 & 13.9 & $<0.001$ \\
\hline off-peak & -5.993 & {$[-6.954,-5.032]$} & -0.012 & -12.2 & $<0.001$ \\
\hline \multicolumn{6}{|l|}{ Schedule deviation at start } \\
\hline Early (s) & -0.585 & {$[-0.613,-0.557]$} & -0.038 & -41.0 & $<0.001$ \\
\hline delayed (s) & 0.031 & {$[0.027,0.034]$} & 0.017 & 18.5 & $<0.001$ \\
\hline \multicolumn{6}{|l|}{ Temperature (ref.: $>0{ }^{\circ} \mathrm{C}$ ) } \\
\hline$\leq 0^{\circ} \mathrm{C}$ & 2.705 & {$[1.281,4.128]$} & 0.004 & 3.7 & $<0.001$ \\
\hline Precipitation $(\mathrm{mm} / \mathrm{h})$ & 0.964 & {$[0.282,1.646]$} & 0.003 & 2.8 & 0.006 \\
\hline Wind $(\mathrm{m} / \mathrm{s})$ & 0.274 & {$[-0.004,0.551]$} & 0.002 & 1.9 & 0.053 \\
\hline Snow $(\mathrm{m})$ & 62.581 & {$[45.397,79.765]$} & 0.007 & 7.1 & $<0.001$ \\
\hline \multicolumn{6}{|l|}{ Stops made } \\
\hline Category 2 & 39.637 & {$[39.163,40.111]$} & 0.191 & 164.0 & $<0.001$ \\
\hline Category 3 & 42.351 & {$[41.183,43.519]$} & 0.068 & 71.1 & $<0.001$ \\
\hline
\end{tabular}

Model statistics

$F=96,018 ; p<0.001 ; N=67,068 ;$ adjusted $R^{2}=0.945$

$b=$ unstandardised coefficient $; 95 \% \mathrm{CI}=95 \%$ confidence interval for $b ; \beta=$ standardised coefficient 
values. Buses departing from a time point ahead of schedule are slower than buses departing on time. Buses departing behind schedule are also somewhat slower. The weather variables have a relatively limited impact. For example, bus travel times are roughly $3 \mathrm{~s}$ longer if the temperature is below zero. Rain or snowfall will typically cause even less additional travel time, except for some rare cases with exceptionally heavy rainfall. Maximum precipitation in the sample is $18 \mathrm{~mm}$ during $1 \mathrm{~h}$, which would correspond to $17 \mathrm{~s}$ additional travel time according to the regression model. Snow depth has a larger coefficient, but the maximum snow depth in the sample is $0.16 \mathrm{~m}$, so the impact is still relatively limited.

Each stop made at a bus stop on the time-point segment increases bus travel time by $40 \mathrm{~s}$ on average for secondary bus stops in urban areas (category 2), and by $42 \mathrm{~s}$ on average for rural bus stops (category 3 ). These variables have the highest values regarding the standardised coefficient $(\beta)$ among the variables that determine the travel time variability on each time-point segment. This indicates that bus stops along the time-point segments, in particular for category 2, have a greater impact on the travel time variability than any of the other variables.

In the second model, the run time model shown in Table 5, the coefficients $(b)$ for number of stops made correspond to the average time needed for deceleration and acceleration. As the bus stops in category 3 are located along roads with higher speed limits, the coefficient is larger for category 3 (26 s) than for category 2 (19s).

Table 5 Regression results with run time (in seconds) as the dependent variable

\begin{tabular}{|c|c|c|c|c|c|}
\hline & $b$ & $95 \% \mathrm{CI}$ & $\beta$ & $t$ & $p$ \\
\hline Constant & 8.266 & {$[6.835,9.696]$} & - & 11.3 & $<0.001$ \\
\hline Free-flow run time (s) & 1.153 & {$[1.150,1.156]$} & 0.891 & 774.5 & $<0.001$ \\
\hline \multicolumn{6}{|l|}{ Period (ref.: inter-peak) } \\
\hline a.m. peak & 14.289 & {$[12.837,15.741]$} & 0.018 & 19.3 & $<0.001$ \\
\hline p.m. peak & 12.802 & {$[11.315,14.290]$} & 0.016 & 16.9 & $<0.001$ \\
\hline off-peak & -6.897 & {$[-7.792,-6.001]$} & -0.015 & -15.1 & $<0.001$ \\
\hline \multicolumn{6}{|c|}{ Schedule deviation at start } \\
\hline Early (s) & -0.602 & {$[-0.628,-0.576]$} & -0.042 & -45.2 & $<0.001$ \\
\hline Delayed (s) & 0.026 & {$[0.023,0.029]$} & 0.016 & 17.0 & $<0.001$ \\
\hline \multicolumn{6}{|c|}{ Temperature (ref.: $>0{ }^{\circ} \mathrm{C}$ ) } \\
\hline$\leq 0{ }^{\circ} \mathrm{C}$ & 2.368 & {$[1.042,3.694]$} & 0.003 & 3.5 & $<0.001$ \\
\hline Precipitation $(\mathrm{mm} / \mathrm{h})$ & 0.721 & {$[0.086,1.356]$} & 0.002 & 2.2 & 0.026 \\
\hline Wind $(\mathrm{m} / \mathrm{s})$ & 0.112 & {$[-0.147,0.370]$} & 0.001 & 0.8 & 0.398 \\
\hline Snow $(\mathrm{m})$ & 64.068 & {$[48.062,80.074]$} & 0.007 & 7.8 & $<0.001$ \\
\hline \multicolumn{6}{|l|}{ Stops made } \\
\hline Category 2 & 19.176 & {$[18.735,19.617]$} & 0.100 & 85.2 & $<0.001$ \\
\hline Category 3 & 25.901 & {$[24.813,26.989]$} & 0.045 & 46.7 & $<0.001$ \\
\hline
\end{tabular}

Model statistics

$F=94,510 ; p<0.001 ; N=67,068 ;$ adjusted $R^{2}=0.944$

$b=$ unstandardised coefficient; $95 \% \mathrm{CI}=95 \%$ confidence interval for $b ; \beta=$ standardised coefficient 
All other variables have similar coefficients as in the first model, meaning that they affect bus travel time and run time similarly.

Finally, the third model, presented in Table 6, suggests that dwell time at bus stops along the time-point segment is defined primarily by the number of stops made and by the passenger activity at these stops. The coefficient for stops made in this case represents the technical dwell time, i.e. the time for opening and closing doors, and the waiting time for the bus to merge back into traffic. The average technical dwell time is $9 \mathrm{~s}$ per stop at bus stops in category 2 and $10 \mathrm{~s}$ per stop at bus stops in category 3 . A boarding passenger adds approximately $8 \mathrm{~s}$ to the dwell time, an alighting passenger adds about $2 \mathrm{~s}$, and the negative squared terms indicate that the time associated with passenger boardings and alightings decreases with each additional passenger. All buses on the studied service are low-entry buses, which is a contributing factor to the relatively short boarding and alighting times.

The variables for the number of stops made, boardings, alightings, and their squared terms are correlated, causing potential multicollinearity issues in the dwell time model, indicated by a maximum variance inflation factor (VIF) score of 6.0.

Table 6 Regression results with dwell time (in seconds) as the dependent variable

\begin{tabular}{|c|c|c|c|c|c|}
\hline & $B$ & $95 \% \mathrm{CI}$ & $\beta$ & $t$ & $p$ \\
\hline Constant & -0.549 & {$[-1.062,-0.035]$} & - & -2.1 & 0.036 \\
\hline \multicolumn{6}{|l|}{ Period (ref.: inter-peak) } \\
\hline a.m. peak & -2.049 & {$[-2.854,-1.244]$} & -0.020 & -5.0 & $<0.001$ \\
\hline p.m. peak & -1.740 & {$[-2.549,-0.930]$} & -0.016 & -4.2 & $<0.001$ \\
\hline Off-peak & 1.702 & {$[1.301,2.104]$} & 0.033 & 8.3 & $<0.001$ \\
\hline \multicolumn{6}{|c|}{ Schedule deviation at start } \\
\hline Early (s) & 0.065 & {$[0.052,0.078]$} & 0.037 & 9.8 & $<0.001$ \\
\hline Delayed (s) & 0.000 & {$[-0.001,0.001]$} & 0.000 & 0.0 & 0.979 \\
\hline \multicolumn{6}{|c|}{ Temperature (ref.: $>0{ }^{\circ} \mathrm{C}$ ) } \\
\hline$\leq 0^{\circ} \mathrm{C}$ & 0.215 & {$[-0.418,0.848]$} & 0.003 & 0.7 & 0.505 \\
\hline Precipitation $(\mathrm{mm} / \mathrm{h})$ & 0.132 & {$[-0.148,0.412]$} & 0.003 & 0.9 & 0.355 \\
\hline Wind $(\mathrm{m} / \mathrm{s})$ & 0.098 & {$[-0.028,0.225]$} & 0.006 & 1.5 & 0.128 \\
\hline Snow (m) & -2.847 & {$[-11.212,5.517]$} & -0.003 & -0.7 & 0.505 \\
\hline \multicolumn{6}{|l|}{ Stops made } \\
\hline Category 2 & 9.118 & {$[8.682,9.554]$} & 0.302 & 41.0 & $<0.001$ \\
\hline Category 3 & 9.694 & {$[9.016,10.372]$} & 0.114 & 28.0 & $<0.001$ \\
\hline \multicolumn{6}{|l|}{ Passenger activity } \\
\hline Boardings & 8.237 & {$[8.010,8.464]$} & 0.640 & 71.1 & $<0.001$ \\
\hline Boardings squared & -0.213 & {$[-0.226,-0.200]$} & -0.215 & -31.2 & $<0.001$ \\
\hline Alightings & 2.074 & {$[1.694,2.455]$} & 0.099 & 10.7 & $<0.001$ \\
\hline Alightings squared & -0.112 & {$[-0.155,-0.068]$} & -0.038 & -5.1 & $<0.001$ \\
\hline
\end{tabular}

Model statistics

$F=3039 ; p<0.001 ; N=24,944$; adjusted $R^{2}=0.646$

$b=$ unstandardised coefficient $; 95 \% \mathrm{CI}=95 \%$ confidence interval for $b ; \beta=$ standardised coefficient 
Therefore, a sensitivity analysis was conducted by removing the squared terms for boardings and alightings from the model. As a consequence, the maximum VIF score decreased to 2.7, suggesting a low risk of multicollinearity (Zuur et al. 2010). The resulting coefficients for boardings and alightings also decreased (to 5.3 and 0.5, respectively), which could be expected, as the decreasing effect for each additional passenger had been removed. The coefficients for the number of stops made instead increased somewhat (to a value of 12 for both bus stop categories), and this modest change suggests relatively stable results. The effect on all other coefficients was negligible. Due to higher explanatory power in the original model, the squared terms are included in the regression results reported in Table 6. Furthermore, because the potential multicollinearity issues were related to boardings and alightings, no multicollinearity issues were detected in the travel time and run time models (maximum VIF score 1.7 in both models).

The sensitivity analysis was also extended to include crossed terms between the time of day and the number of stops made. The results showed no substantial effect from the crossed terms, neither on the other coefficients nor on the explanatory power of the models. For the sake of simplicity, these crossed terms are therefore omitted in the reported regression models.

To sum up, the number of stops made has a substantial effect on travel time variability on the studied bus service, a seemingly greater effect than any of the other variables, such as the weather or traffic conditions during peak hours. Moreover, added bus travel time due to deceleration, acceleration, and technical dwell time far exceeds the average dwell time related to passenger activity. A typical stop with one boarding passenger means approximately $40 \mathrm{~s}$ additional bus travel time, but only about 8 of those $40 \mathrm{~s}$ stem from the boarding process.

\subsection{Route level analysis}

The part of the bus service that is in focus for the route level analysis (Broby-Kristianstad) includes 21 intermediate bus stops. However, all these 21 stops are never used simultaneously on a single bus trip in the sample. The distribution of the number of stops made is shown in Fig. 6. As can be seen in the figure, the actual number of stops made vary from 1 to 15 , and on an average bus trip, only seven of the 21 bus stops are used.

In order to further explore the variability in stopping patterns, stop distributions for each bus stop category are presented in Table 7. In category 1, almost all buses stop at two of the three bus stops between Broby and Kristianstad (excluding the termini). The third bus stop in this category is less frequented, resulting in an average of 2.3 stops per bus trip. The relatively high level of usage, together with the fact that they are few in numbers, mean that bus stops in category 1 affect overall variability to a comparatively small extent.

In contrast, the number of stops made at bus stops in category 2 vary considerably. The share of bus trips that stop at an individual bus stop in this category, the stopping rate, ranges from 20 to $70 \%$, but is close to $50 \%$ at most bus stops in this category. The stopping rates are higher during peak hours and lower during 


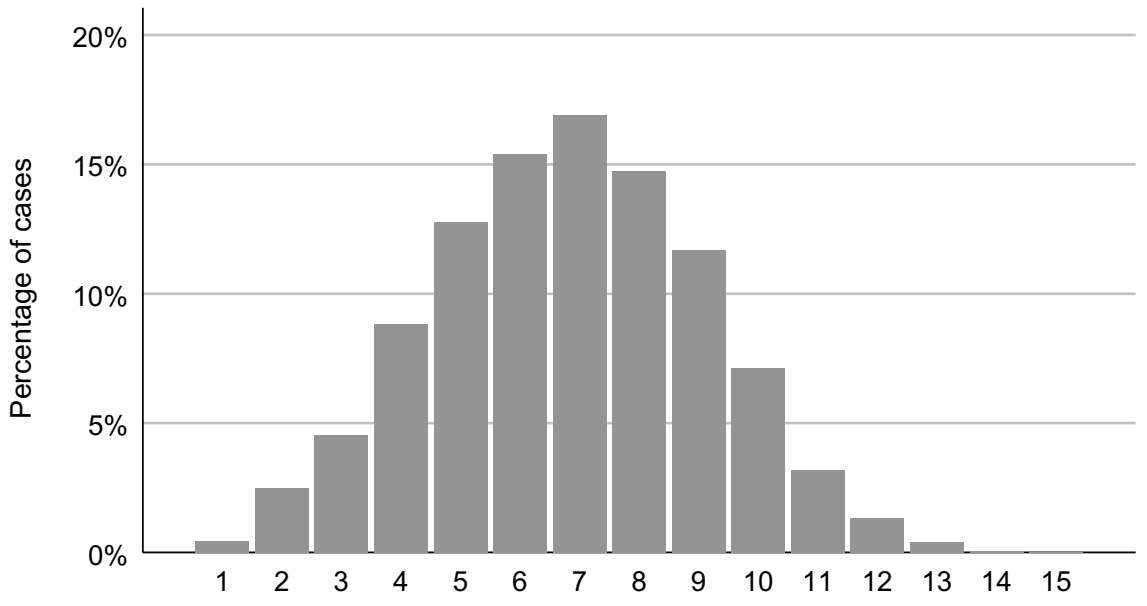

Number of stops made en route

Fig. 6 Distribution of the number of stops made en route, excluding the two termini $(N=10,645)$

Table 7 Statistics of number of stops made en route per bus stop category, excluding the two termini $(N=10,645)$

\begin{tabular}{lllll}
\hline & Category 1 & Category 2 & Category 3 & Total \\
\hline $\begin{array}{l}\text { Scheduled stops } \\
\text { Stops made }\end{array}$ & 3 & 8 & 10 & 21 \\
$\quad$ Maximum & 3 & 8 & 5 & 15 \\
$\quad$ Mean & 2.3 & 3.9 & 0.6 & 6.8 \\
$\quad$ Standard deviation & 0.5 & 1.8 & 0.8 & 2.3 \\
Percentiles & & & & \\
5th percentile & 2 & 1 & 0 & 3 \\
Median & 2 & 4 & 0 & 7 \\
95th percentile & 3 & 7 & 2 & 11 \\
\hline
\end{tabular}

off-peak, and as a result, the total number of stops made at bus stops in this category vary from none to all eight of them. The standard deviation of the number of stops made in this category is considerably higher than in the other two categories.

Category 3 bus stops make up almost half of all scheduled intermediate stops, but they are so infrequently used that it is rare for more than two of them to be used on a single bus trip. The stopping rates in this category range from fractions of a percentage to $30 \%$, with typical values around $5 \%$. As a result, most bus trips do not stop at any of the category-3 bus stops. Nevertheless, they do affect overall variability, but to a considerably smaller extent than the category-2 bus stops.

By combining the results from the time-point segment analysis with the average number of stops made at route level, it is possible to estimate the effects on average travel time. These turn out to be rather moderate. The eight bus stops in category 2 cause an average of $144 \mathrm{~s}$ added travel time and the ten bus stops in category 3 cause an additional $26 \mathrm{~s}$. This is a little less than 3 mins in total. As a comparison, the scheduled travel time, as well as the average travel time in the sample, is $38 \mathrm{~min}$. 
The effect on travel time variability is more tangible. This is illustrated by the line chart in Fig. 7, where the reliability buffer index is plotted against the number of stops made en route. In this case, the reliability buffer index compares the $95^{\text {th }}$ percentile of travel time in each class with the average travel time in the total sample. Cases with 1-2 stops and cases with 11-15 stops have been binned in order to create large enough groups for the analysis. As can be seen in the chart, the risk of travel times that are substantially higher than average increases as the number of stops made increases, at least if the number of served stops exceeds three. Considering the distribution of the number of stops made together with the high index scores to the right in the chart, cases with many stops are very influential on the travel time dispersion in the total sample. Consequently, the reliability buffer index of the entire sample is as high as $11.6 \%$. Still, it is lower than on the individual time-point segments (see Table 2), due to the possibility of adjusting the schedule at the intermediate time points at the route level.

As a consequence of the travel time variability, the on-time performance of arrivals at the terminus also depends on the number of stops made en route. The proportion of buses arriving less than 3 mins delayed is $74 \%$ in the sample, overall; but for buses stopping at four or fewer bus stops it is well above $90 \%$. On the other end of the spectrum, the on-time performance for cases stopping at more than ten bus stops is as low as $30 \%$. This is illustrated in Fig. 8, where on-time performance is plotted against the number of stops made en route. Also, the distribution of the number of stops is included in the figure, through the width of the bars, allowing the influence of each class to be assessed.

With the scheduled travel time roughly equal to the average travel time, there is an obvious relation between the reliability buffer index and the on-time performance. For cases with more than three stops en route, there is a clear drop in ontime performance for every additional stop made.

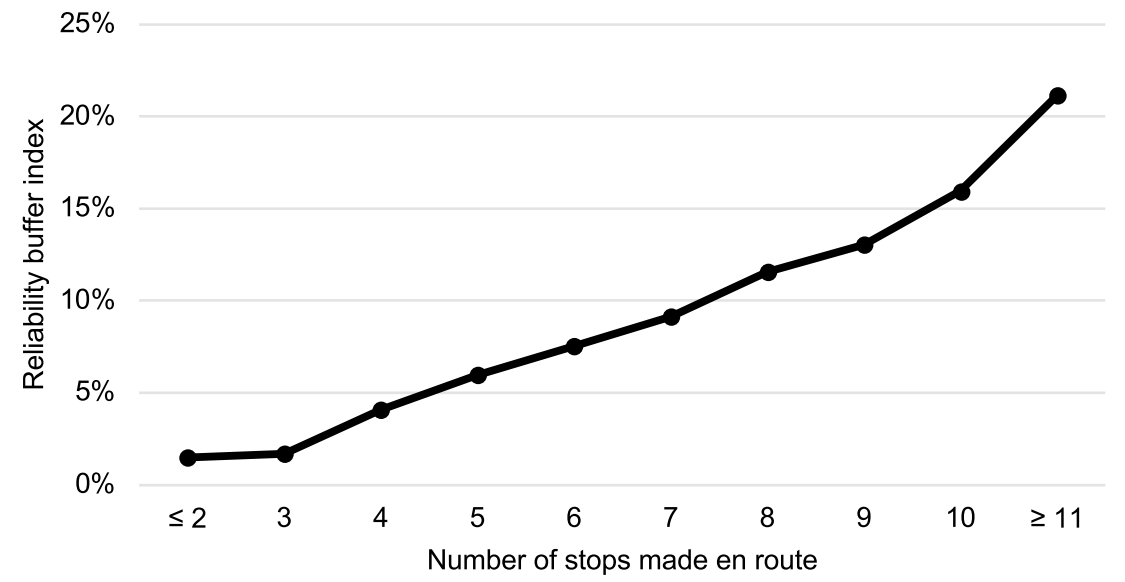

Fig. 7 Reliability buffer index against the number of stops made en route, depicting the relative difference between the $95^{\text {th }}$ percentile of travel time in each class and the average travel time in the total sample $(N=10,465)$ 


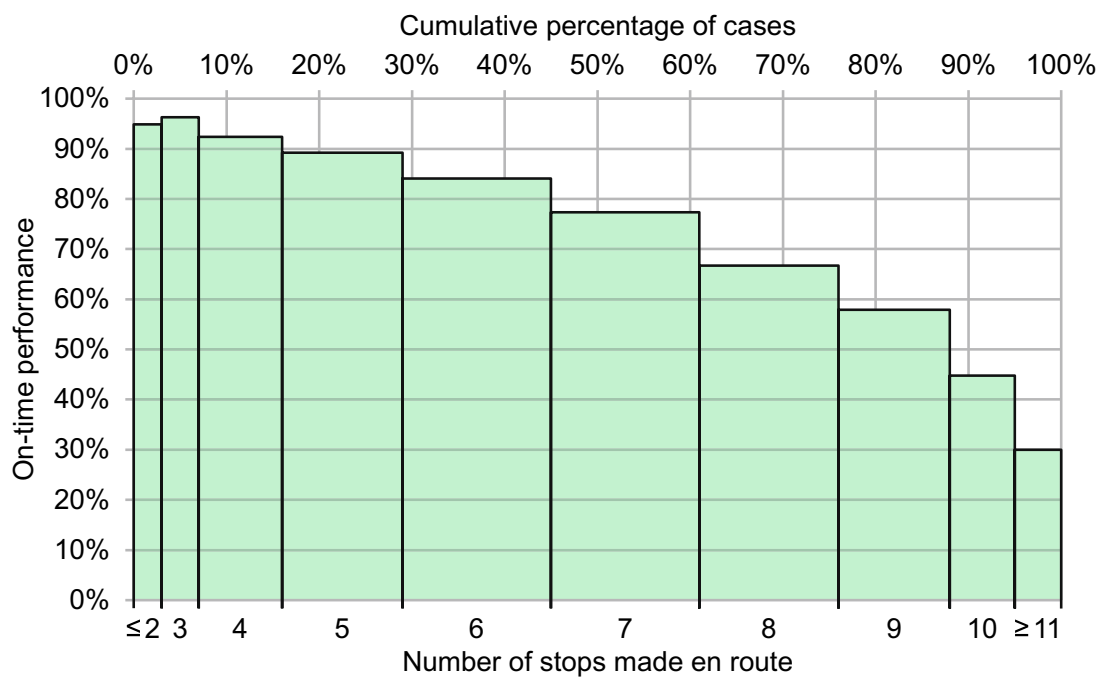

Fig. 8 On-time performance (percentage of arrivals less than 3 mins delayed) against number of stops made, where the width of the bars correspond to the distribution of the number of stops made $(N=10,465)$

\section{Discussion}

The overall purpose of this study was to increase knowledge about the impact of rural bus stops on average travel times as well as reliability. To this end, bus stops on a regional bus service were categorised with regard to the location and function of the stops, using three categories: main bus stops in urban areas, secondary bus stops in urban areas, and rural bus stops (outside urban areas).

Regarding average travel times, the results from the chosen, fairly rural, study district suggest that rural bus stops have very little impact. Every stop adds, on average, about $40 \mathrm{~s}$ to the travel time of a bus trip, but rural bus stops are normally used so infrequently that their impact on the average travel time is practically negligible overall. On the studied bus service, a typical rural bus stop adds just 2-3 s to the average travel time. In comparison, secondary bus stops in urban areas are used more frequently, so their impact on average travel time is more substantial. Still, the impact is relatively moderate in comparison with total travel time.

However, the impact on reliability is much more tangible. Many stops with sporadic usage imply a large variability in actual stopping patterns, which in turn impacts on travel time variability. The results of the time-point segment analysis indicate that the number of stops made has a far greater impact on travel time variability than any of the other included variables, such as the weather or traffic conditions during peak hours. It is acknowledged that the included variables do not cover all aspects with a possible impact on travel time variability. For example, driver experience may have a statistically significant impact, but is omitted in this study due to a lack of data. However, its level of impact is expected to be relatively small (El-Geneidy et al. 2011). In a more congested area, the impact of traffic conditions 
is likely to increase, but the results suggest that stopping patterns would still in any case be very important to consider in order to improve reliability.

The results of the route level analysis illustrate the impact of travel time variability on overall on-time performance. The probability of arriving on time clearly depends on the number of stops made.

Thus, the results suggest that stop spacing on regional bus services largely implies a trade-off between coverage and reliability rather than between coverage and travel time. This means that approaches for assessing bus stops based only on travel time are too simplistic and risk ignoring the most substantial effects. Reliability is commonly among the top priorities for regional passengers, as is travel time (Hansson et al. 2019), which means that poor on-time performance cannot generally be solved through increased margins in the timetable. The timetable margins also affect operational costs, further stressing the importance of minimising travel time variability (El-Geneidy et al. 2006).

Analogous to the impacts on average travel times, the results suggest that rural bus stops have less of an impact on reliability than secondary bus stops in urban areas. On the studied bus service, the proportion of buses stopping are typically around $50 \%$ at the secondary bus stops in urban areas. This is the worst-case scenario for travel time variability. Stopping rates closer to 0 , or closer to $100 \%$, imply less variability in the total number of stops made.

Consequently, in order to improve reliability, it would be reasonable to, first and foremost, focus on secondary bus stops in urban areas. This may seem irrational, as rural bus stops generally have lower levels of passenger activity and are therefore more often disputed. However, not only do the secondary bus stops in urban areas have a larger impact on reliability, they are also usually located relatively close to other bus stops. This means that removing such a bus stop will not make the service entirely inaccessible, and the consequence for most people will rather be limited to longer access distances. In addition, the results of the regression analyses show that most of the added travel time at a stop is related to deceleration, acceleration, and technical dwell time. This further stresses the fact that it may be beneficial to concentrate passenger activity (boardings and alightings) on fewer bus stops. The longer access distances may be compensated with a higher level of service (van Soest et al. 2020), in terms of improved reliability.

Outside of urban areas, the trade-off between coverage and reliability is more clear-cut. Access distances there generally become too long when a bus stop is removed, unless remaining stops are upgraded in terms of service quality as well as car and bicycle access (Hansson et al. 2021). This can be crucial for the parts of the rural population who are dependent on public transport in their everyday lives (Berg and Ihlström 2019), but also important for others, whose mobility options become restricted to car travel (Bondemark and Johansson 2017). In general, the impact of rural bus stops on travel time variability is also less substantial, which means that several of them need to be removed in order to achieve an improvement in the same order of magnitude as from removing a single secondary bus stop in an urban area. Thus, by focusing on bus stop consolidation in urban areas, despite the generally higher levels of passenger activity, it is possible to significantly improve reliability without impairing coverage in rural areas. 
In cases where the rural bus stops are more frequented or more densely spaced, their level of impact will increase. In those cases, it is reasonable to place greater emphasis on the rural bus stops. Nevertheless, unless the preconditions are widely different from the case studied in this article, it is likely that secondary bus stops in urban areas will still have a more substantial impact. They are also in most cases less crucial in terms of coverage.

As for analyses and impact assessments of different types of bus stops in different contexts, the method presented in this article offers a feasible approach. By combining methods previously used for analysis of rail traffic and urban bus operations, this article demonstrates a relatively simple and useful approach to analyse large volumes of data about bus movements on a regional bus service. The time-point segment analysis and the route level analysis can be used either in combination or separately, depending on whether the study focuses on details about dwell times, etc. or aggregate effects regarding on-time performance.

In practice, an application of the method is neither limited to regional bus services, nor to the specific bus stop categories used in this article. Future implementations may therefore include other types of services, with bus stop categories adapted to the purpose of the specific study.

\section{Conclusions}

This study shows that bus stops that are only used sporadically have limited impact on average travel times, but are more influential on travel time variability. These types of bus stops, that are common on regional bus services, lead to inconsistent stopping patterns. The results show that this inconsistency has a major impact on the reliability of the bus service.

Furthermore, the results suggest that rural bus stops have a lower impact on reliability than what we define as secondary bus stops in urban areas. Consequently, in order to improve reliability, it would be reasonable to initially focus on secondary bus stops in urban areas. This may seem irrational, as rural bus stops generally have lower levels of passenger activity and are therefore more often disputed. However, not only do the rural bus stops have a lower impact on reliability, they are also generally more crucial for the coverage of the bus service. By focusing primarily on bus stop consolidation in urban areas, it is possible to maintain coverage in rural areas and still significantly improve service reliability. Broadly, this would mean longer access distances for some, but improved reliability for all passengers.

The study also demonstrates a method for analysing bus travel times, specifically adapted for assessing different types of bus stops. The method is primarily based on automatic vehicle location (AVL) data on a bus-stop level, which offer a large number of bus trips to be included in the analysis. The large amount of data, in turn, enables a detailed understanding of the causes of travel time variability.

Authors' contributions JH: Conceptualisation; Formal analysis; Investigation; Methodology; Visualisation; Writing—original draft. FP-L: Supervision; Writing—review and editing. HS: Supervision; Writing-review and editing. AW: Supervision; Writing-review and editing. 
Funding Open access funding provided by Lund University. This study was funded by the Swedish Transport Administration through K2-The Swedish Knowledge Centre for Public Transport.

Availability of data and material The data used and analysed during the current study are available from the corresponding author on reasonable request.

Code availability Not applicable.

\section{Declarations}

Conflict of interest The authors have no conflicts of interest to declare that are relevant to the content of this article.

Open Access This article is licensed under a Creative Commons Attribution 4.0 International License, which permits use, sharing, adaptation, distribution and reproduction in any medium or format, as long as you give appropriate credit to the original author(s) and the source, provide a link to the Creative Commons licence, and indicate if changes were made. The images or other third party material in this article are included in the article's Creative Commons licence, unless indicated otherwise in a credit line to the material. If material is not included in the article's Creative Commons licence and your intended use is not permitted by statutory regulation or exceeds the permitted use, you will need to obtain permission directly from the copyright holder. To view a copy of this licence, visit http://creativecommons.org/licen ses/by/4.0/.

\section{References}

Berg J, Ihlström J (2019) The importance of public transport for mobility and everyday activities among rural residents. Soc Sci 8:58. https://doi.org/10.3390/socsci8020058

Bondemark A, Johansson E (2017) Optionsvärden i kollektivtrafiken (K2 working papers 2017:2). K2, Lund

Büchel B, Corman F (2020) Review on statistical modeling of travel time variability for road-based public transport. Front Built Environ 6:1-14. https://doi.org/10.3389/fbuil.2020.00070

Chen J, Currie G, Wang W, Liu Z, Li Z (2016) Should optimal stop spacing vary by land use type? New methodology. Transp Res Rec 2543:34-44. https://doi.org/10.3141/2543-04

Currie G (2016) Managing on-road public transport. In: Bliemer M, Mulley C, Moutou CJ (eds) Handbook on transport and urban planning in the developed world. Edward Elgar Publishing, Cheltenham, UK, pp 471-497

El-Geneidy AM, Strathman JG, Kimpel TJ, Crout DT (2006) Effects of bus stop consolidation on passenger activity and transit operations. Transp Res Rec 1971:32-41. https://doi.org/10.3141/1971-06

El-Geneidy AM, Horning J, Krizek KJ (2011) Analyzing transit service reliability using detailed data from automatic vehicular locator systems. J Adv Transp 45:66-79. https://doi.org/10.1002/atr.134

Fritz CO, Morris PE, Richler JJ (2012) Effect size estimates: current use, calculations, and interpretation. J Exp Psychol Gen 141:2-18. https://doi.org/10.1037/a0024338

Hansson J, Pettersson F, Svensson H, Wretstrand A (2019) Preferences in regional public transport: a literature review. Eur Transp Res Rev 11:38. https://doi.org/10.1186/s12544-019-0374-4

Hansson J, Pettersson-Löfstedt F, Svensson H, Wretstrand A (2021) Replacing regional bus services with rail: changes in rural public transport patronage in and around villages. Transp Policy 101:89-99. https://doi.org/10.1016/j.tranpol.2020.12.002

Hu WX, Shalaby A (2017) Use of automated vehicle location data for route- and segment-level analyses of bus route reliability and speed. Transp Res Rec 2649:9-19. https://doi.org/10.3141/2649-02

Lin M, Lucas HC, Shmueli G (2013) Too big to fail: large samples and the p-value problem. Inf Syst Res 24:906-917. https://doi.org/10.1287/isre.2013.0480

Luke D, Steer J, White P (2018) Interurban Bus Time to raise the profile. Greengauge 21

Martens K (2004) The bicycle as a feedering mode: experiences from three European countries. Transp Res Part D Transp Environ 9:281-294. https://doi.org/10.1016/j.trd.2004.02.005 
Midenet S, Côme E, Papon F (2018) Modal shift potential of improvements in cycle access to exurban train stations. Case Stud Transp Policy 6:743-752. https://doi.org/10.1016/j.cstp.2018.09.004

Mulley C, Ho C, Ho L, Hensher D, Rose J (2018) Will bus travellers walk further for a more frequent service? An international study using a stated preference approach. Transp Policy 69:88-97. https:// doi.org/10.1016/j.tranpol.2018.06.002

Murray AT, Wu X (2003) Accessibility tradeoffs in public transit planning. J Geogr Syst 5:93-107. https://doi.org/10.1007/s101090300105

Nielsen G, Nelson JD, Mulley C et al (2005) HiTrans best practice guide 2: public transport - planning the networks. HiTrans, Oslo

Palmqvist CW, Olsson NOE, Hiselius L (2017) Delays for passenger trains on a regional railway line in southern Sweden. Int J Transp Dev Integr 1:421-431. https://doi.org/10.2495/TDI-V1-N3-421-431

Pettersson F (2018) Developing a regional superbus concept—collaboration challenges. Case Stud Transp Policy 6:32-42. https://doi.org/10.1016/j.cstp.2017.12.003

Shrestha RM, Zolnik EJ (2013) Eliminating bus stops: evaluating changes in operations, emissions and coverage. J Public Transp 16:1-23. https://doi.org/10.5038/2375-0901.16.4.1

Statistics Sweden (2020) Localities and urban areas. https://www.scb.se/en/finding-statistics/statistics-bysubject-area/environment/land-use/localities-and-urban-areas/. Accessed 22 Dec 2020

Stewart C, El-Geneidy A (2016) Don't stop just yet! A simple, effective, and socially responsible approach to bus-stop consolidation. Public Transp 8:1-23. https://doi.org/10.1007/s12469-015-0112-9

Tirachini A (2014) The economics and engineering of bus stops: spacing, design and congestion. Transp Res Part A Policy Pract 59:37-57. https://doi.org/10.1016/j.tra.2013.10.010

van Soest D, Tight MR, Rogers CDF (2020) Exploring the distances people walk to access public transport. Transp Rev 40:160-182. https://doi.org/10.1080/01441647.2019.1575491

Vijayakumar N, El-Geneidy AM, Patterson Z (2011) Driving to suburban rail stations: Understanding variables that affect driving distance and station demand. Transp Res Rec 2219:97-103. https://doi. org/10.3141/2219-12

Walker J (2008) Purpose-driven public transport: creating a clear conversation about public transport goals. J Transp Geogr 16:436-442. https://doi.org/10.1016/j.jtrangeo.2008.06.005

White P (2016) Rural public transport. Public transport: its planning, management and operation, 6th edn. Routledge, Oxford, pp 201-221

Zhao J, Frumin M, Wilson N, Zhao Z (2013) Unified estimator for excess journey time under heterogeneous passenger incidence behavior using smartcard data. Transp Res Part C Emerg Technol 34:7088. https://doi.org/10.1016/j.trc.2013.05.009

Zuur AF, Ieno EN, Elphick CS (2010) A protocol for data exploration to avoid common statistical problems. Methods Ecol Evol 1:3-14. https://doi.org/10.1111/j.2041-210x.2009.00001.x

Publisher's Note Springer Nature remains neutral with regard to jurisdictional claims in published maps and institutional affiliations.

\section{Authors and Affiliations}

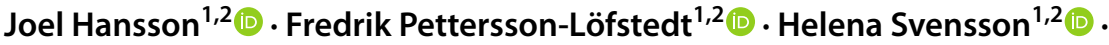 Anders Wretstrand ${ }^{1,2}$ (1)}

Fredrik Pettersson-Löfstedt

fredrik.pettersson-lofstedt@tft.lth.se

Helena Svensson

helena.svensson@tft.lth.se

Anders Wretstrand

anders.wretstrand@tft.lth.se

1 Transport and Roads, Lund University, Box 118, 22100 Lund, Sweden

2 K2 - The Swedish Knowledge Centre for Public Transport, Bruksgatan 8, 22236 Lund, Sweden 